\title{
How many principles of urban ecology are there?
}

\author{
Steward T. A. Pickett • Mary L. Cadenasso
}

Received: 26 September 2016/Accepted: 31 January 2017/Published online: 11 February 2017

(C) The Author(s) 2017. This article is published with open access at Springerlink.com

\begin{abstract}
Context The nature of urban ecology theory is controversial. Issues include whether urban theory is distinct, whether it has principles, and whether those principles differ from those for non-urban systems. Recently, Richard Forman enumerated urban ecology principles, while we have previously articulated different urban ecology principles. This raises the question of whether there are legitimately different sets of principles.

Objectives Recognizing the legitimacy of Forman's principles, we wish to determine whether different methodological assumptions can lead to different sets of urban ecology principles.

Methods We contrast Forman's 90 urban ecology principles with our much smaller set to determine why they differ in detail, empirical motivation, and generality. We identify the approaches that generate each set of principles, and seek an inclusive framework to integrate them.
\end{abstract}

Results The alternative sets represent contrasting approaches to identifying principles: Forman's approach is more inductive, generating principles

S. T. A. Pickett ( $\square)$

Cary Institute of Ecosystem Studies, Box AB, Millbrook, NY 12545, USA

e-mail: picketts@caryinstitute.org

M. L. Cadenasso

Department of Plant Sciences, University of California,

Davis, 1 Shields Ave., Davis, CA 95616, USA from a body of empirical cases, while our concise roster is more deductive, focusing on general ideas from which the details of specific cases can be derived. Both are legitimate.

Conclusions Principles of urban ecology can arise from inductive empirical generalization within specified ecological, cultural, and historical contexts, as shown by Forman. However, urban ecology principles can also emerge from a more general, synthetic impulse as we have shown. Neither approach is necessarily better. Both can contribute to a comprehensive theoretical hierarchy that can advance urban ecology.

Keywords Deductive - Generalization - Inductive · Synthesis · Theory · Urban ecology

\section{Introduction}

Forman (2016) has published in this journal an extensive and well-justified roster of principles for the science of urban ecology. This compilation owes much to his own international experience in urban ecology, design, and regional planning (Forman 2008), and to his comprehensive textbook on the discipline (Forman 2014). While we were impressed with his compilation, and find it useful, we were intrigued by the fact that it differed from our own earlier attempts to articulate and organize principles 
for urban ecology (e.g. Cadenasso and Pickett 2008). This essay explores why there might be different sets of principles of urban ecology. We seek to determine whether the alternative enumeration of principles might expose different assumptions about the science and its theory. We are also interested to determine whether the sets are complementary in some way. We hope this exploration helps move this still young discipline toward the theory that is often called for (Alberti 2008; Niemelä et al. 2009; McPhearson et al. 2016).

Our exploration of urban ecology principles began in 2007, when we participated in a conference on "Ecological Landscaping: From Scientific Principles to Public Practices and Policy." The meeting was aimed at landscape architects and landscaping practitioners. Consequently, we wanted to distill key insights of urban ecological science in a digestible form that could be linked to landscape design and management. We later published our contribution as a short paper on the principles of urban ecology (Cadenasso and Pickett 2008).

We generated five general principles to satisfy the intellectual and practical requirements of the conference: (1) cities are ecosystems; (2) cities are spatially heterogeneous; (3) cities are dynamic; (4) cities link human and natural processes; and (5) ecological processes continue to operate in cities (Cadenasso and Pickett 2008). We discussed some of the design, planning, and management implications for each of these principles, to make them useful for the audience. Our continued work with principles has also been shaped by our interactions with urban designers and landscape architects (Spirn 1984; Nassauer 1995; McGrath et al. 2007; Musacchio 2009, 2013; Felson et al. 2013; McGrath 2013). We believe that such abstractions of the essence of urban ecology have value to researchers and students within these evolving disciplines as well.

\section{What is a principle?}

The term principle is actually rather vague. According to our review of philosophical literature (Pickett et al. 2007), a principle can refer to any of the conceptually oriented components of theory. For example, a principle can be a concept, a definition used to translate concepts to specific cases, a definition of a quantitative convention within a model, a confirmed empirical generalization, or a law. Although principles interact with facts and observations, they are not the same as individual facts or even collections of facts. Principles can be derived inductively by aggregating individual observations or facts; however, construction of principles from facts involves some degree of abstraction, idealization, summarization, and the identification of relationships among observations or other parts of theory.

To be fair, we did not specify exactly what kind of conceptual "thing" our five principles were in 2008. In part, this was because there was no mature, complete theory with a clear framework that could be used to identify what specific role each principle played in a larger conception of urban ecology. We believe that is still the case today.

Later, we expanded the roster of principles by digging deeper into mechanisms, the cross-disciplinary nature of urban ecology, and some widespread concerns that would support the linkage of the science to practices well beyond landscaping. That analysis appeared in a massive encyclopedia (Pickett and Cadenasso 2012) but is being refined as part of ongoing efforts in the Baltimore Ecosystem Study (beslter.org). In that expanded version, we enumerated 13 principles, providing more detail in several of the statements (Table 1).

\section{What do principles do?}

These 13 more detailed principles (Table 1) explain or nest within the five general principles laid out in 2008 (Fig. 1; Cadenasso and Pickett 2008). This suggests that there can be levels of generality of principles, with some being very "high level" or general, whereas others are more focused and related to specific models. In fact, the short list of principles, because of their higher degree of abstraction and consequently broader scope, can be identified as "metaprinciples." The prefix meta in this case is used in the sense of "beyond" the individual, more detailed principles (Table 1). The difference between the highest level metaprinciples, the thirteen nested general principles, and then the principles that operate through specific models suggests that the emerging theory of urban ecology has-like so many theories in science-a nested hierarchical structure (Fig. 1). Examples of 
Table 1 A more complete and detailed enumeration of urban ecology principles

1. Cities and urban areas are human ecosystems in which social-economic and ecological processes feed back to one another

2. Urban areas contain remnant or newly emerging vegetated and stream patches that exhibit ecological functions

3. Urban flora and fauna are diverse, and this diversity has multiple dimensions (e.g. taxonomy, phylogenetics, function, geographic origin)

4. Human values and perceptions are a key link mediating the feedbacks between social and ecological components of human ecosystems

5. Ecological processes are differentially distributed across the metropolis and the limitation of services and excess of hazards is often associated with the location of human communities that are poor, discriminated against, or otherwise disempowered

6. Urban form is heterogeneous on many scales, and fine-scale heterogeneity is especially notable in cities and older suburbs

7. Urban form reflects planning, incidental, and indirect effects of social and environmental decisions

8. Urban form is a dynamic phenomenon and exhibits contrasts through time and across regions that express different cultural and economic contexts of urbanization

9. Urban designs and development projects at various scales can be treated as experiments, and used to expose the ecological effects of different design and management strategies

10. Definition of the boundaries and content of an urban system model is set by the researchers based on their research questions or the spatial scope of its intended application

11. Urban comparisons can be framed as linear transects or as abstract gradients, and the abstract comparisons acknowledge the spatial complexity of urban heterogeneity

12. Urban land covers and land uses extend into and interdigitate with rural or wild land covers and uses

13. The flux of water, including both clean water supply, waste, and stormwater management, is of concern to urban and urbanizing areas worldwide, and connects them explicitly to larger regions

Modified from Pickett and Cadenasso (2012)

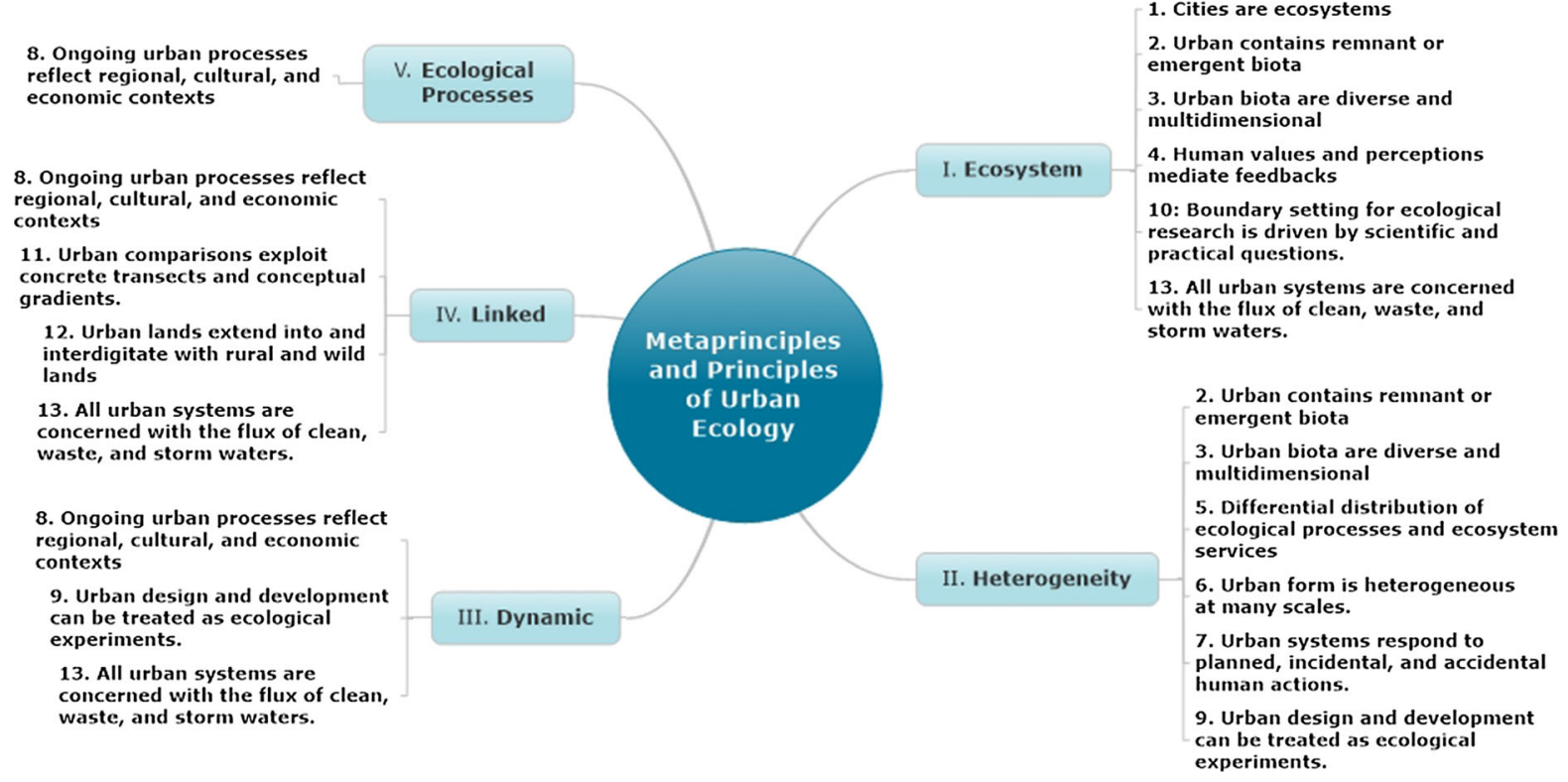

Fig. 1 The thirteen principles of urban ecology (Table 1) nested within the topics of five metaprinciples (Cadenasso and Pickett 2008). The principles appear as distal branches, while the metaprinciples appear as the main branches with labels in the shaded rectangles. This nesting illustrates the hierarchical nature of urban ecological theory. Each of the principles in the outer, distal branches of the diagram would itself comprise more specific principles, models, and sets of observations. Such finer "twigs" are not shown here. Note that a single principle may serve to translate or explain more than one metaprinciple. The labels for the metaprinciples have been simplified to fit in the figure 
hierarchical theory structures relevant to ecology include that of succession or vegetation dynamics (Meiners et al. 2015), and of evolution (Pickett et al. 2007).

Indeed, the theory of ecology in general has been presented as a hierarchy of eight very general principles, with nested constituent theories that address more specific ecological topics and processes (Table 2; Scheiner and Willig 2011). Within each of these constituent theories there are one or more models that spell out detailed mechanisms, temporal and spatial contingencies, rules, and exceptions to the rules. Some of these model components may legitimately be referred to as principles, though the difference between those and the most general principles of an area may not always be evident in the use of the term.

From the discussion above, we can see that principles can perform several important functions for urban ecology and other fields. Principles can:

1. Identify the main concerns of a theory.

2. Serve to link general and specific components of theory.

3. Lay out expectations of mechanism or interaction.

4. Summarize patterns of interest to the theory.

These tasks for principles, and the several hierarchical levels on which principles can exist, suggest that there may be many paths toward principles. Employing principles in each of these ways and hierarchical levels can suggest research needs.

\section{How are principles derived?}

Our approach to principles has been from the top down (e.g. Cadenasso and Pickett 2008). That is, we have been motivated by identifying the most general principles of urban theory, and then sorting out how the details of mechanism or pattern fit within those principles. This approach is a form of deduction from abstract generality.

A bottom-up approach is also possible in which principles are generated inductively by aggregating specific cases. Forman (2016) identifies his list of urban principles using a primarily bottom-up approach. We interpret Forman's strategy as bottomup because his list of the descriptors of science appears in this order: concepts, principles, laws, models, hypotheses, and theories. Forman's order is essentially the familiar inductive series building up increasingly firm or inclusive statements from individual facts or observations (cf. Pickett et al. 2007). In addition, his list of principles that have developed in urban ecology since its 1970 s origin amounts to 90 entries.

The inductive nature of this list is also strongly suggested by Forman's demonstration that the principles reflect the nature of cities in which the research supporting them was conducted. Forman lists 16 details of late nineteenth century cities, and 15 for late twentieth century/early twenty-first century cities, to illustrate the contexts from which the 90 urban principles emerged. It is important that under this approach, the number of principles would be expected to grow as more is learned in different places and times.

One of Forman's main points is that urban ecology, as a collection of empirical generalizations embodied in his 90 principles, is different from the principles that have emerged from the study of natural areas. Thus, urban ecology as a body of knowledge summarized in inductive or data-summarizing principles is (necessarily) different from other kinds of ecology as bodies of knowledge served by their own inductive principles. Forman's search for urban ecology principles appears to be an inductive, place-based pursuit. There is nothing wrong with this approach, but the
Table 2 The eight most general principles of the science of ecology

Modified from Scheiner and Willig (2011, p. 12)
1. Organisms are distributed heterogeneously in space and time

2. Organisms interact with abiotic and biotic environments

3. Variation in the characteristics of organisms results in ecological heterogeneity

4. The distribution of organisms and their interactions are temporally contingent

5. Organisms perceive environmental conditions as heterogeneous in space and time

6. Resources are perceived by organisms as finite and heterogeneous

7. Birth and death rates result from interactions with the abiotic and biotic environment

8. The ecological properties of species are the result of evolution 
differences in approach need to be acknowledged. The inductive approach justifies Niemalä's (1999) view that theory in urban ecology is different from theory in the ecology of wild places. Similarly, Rebele (1994) noted features of urban systems that required different theory from ecology of non-urban systems.

The place-based nature of Forman's principles points to an important opportunity for urban ecology as a global science (McHale et al. 2015). A key point about Forman's inductive approach is that it appears to be biased toward cities of the Global North. Thus, the trajectories of the industrial revolution, the subsequent development of the sanitary city (Melosi 2000), and the nodal role of metropolises in colonial and corporate globalization (Seto et al. 2012) are the boundary conditions for his principles. The rapidly emerging urban realm of the Global South has a different mixture of contexts (McHale et al. 2015). The areas undergoing the most rapid urban conversion today may generate some of the same conditions as have emerged in the cradle of urban ecological science. However, it is very likely that today's urbanization in Asia and Africa will establish some boundary conditions that are quite different (Wu et al. 2014). An important task will be to identify these differences, and to articulate from the top down, or to discover from the bottom up, the empirical generalizations that fit these new situations.

\section{Ecology/ecologies: one science, many models}

The idea of principle is an intentionally flexible one, embodying much power in structuring a science, summarizing its insights, and motivating application. However, the fact that principles point to a hierarchy of generality suggests something about what it means for a subdiscipline or a kind of system to have a "different ecology."

From the perspective of the definition of ecology as a scientific pursuit or process, there is only one ecology: "The scientific study of the processes influencing the distribution and abundance of organisms, the interactions among organisms, and the interactions between organisms and the transformation and flux of energy and matter" (e.g. Likens 1992, p. 8). Urban ecology merely adds an emphasis on human ecosystems in general, which include organisms, the physical environment and conditions, the human population and its social structures and processes, and the built and technological components (Cadenasso et al. 2006; Pickett and Grove 2009). So there is only one ecology - as a way to pursue science-although there are many kinds of system to which it can apply.

From the perspective of science as a body of knowledge, however, there can be several kinds of ecology. These ecologies comprise different specific models or families of model, or sets of generalizations about kinds of systems or historical periods. This is the analytic home for Forman's (2016) conclusion that urban ecology is different from the ecology of wild places. What this means is that the bodies of facts and empirical generalizations-or principles in his parlance-are different when they emerge from urban systems than when they emerge from wild systems. Forman's conclusion parallels analyses of Rebele (1994) and Niemalä (1999) that urban ecology requires different generalizations or boundary conditions.

We hope that this discussion clarifies two things. Urban ecology, which focuses on inhabited and densely built systems, and other kinds of ecology, which focus on uninhabited but in some cases managed or otherwise anthropogenically impacted systems, are the same as a scientific process, and from the perspective of generalizable drivers (e.g. Scheiner and Willig 2011). They are different in terms of the facts and generalizations that apply within their domains. For example, the river continuum model for wild watersheds (Vannote et al. 1980) must be modified by urban facts reflecting engineered infrastructure, altered amounts and locations of organic matter inputs, and stream disconnection from floodplains (Kaushal and Belt 2012). Similarly, the well known urban heat island effect expresses the generalized heat budget within the constraints of altered evapotranspiration and thermal storage capacities of urban environments (e.g. Huang et al. 2011; Lee et al. 2014). Knowing how to array research and conclusions across conceptual gradients connecting built and uninhabited landscapes, is, as Forman (2016) suggests, a crucial frontier for ecological science in a changing, connected world.

\section{And the envelope, please!}

To answer the question posed in our title, there are roughly a half dozen principles of urban ecology when 
one takes a combined top-down and empirical approach, but so far there are on the order of 100 when one takes a bottom-up approach to empirical summarization. These approaches have complementary roles to play in advancing urban ecology, and reconciling them points to a nested hierarchy as a way to promote integrated urban ecological theory. The framework presented in Fig. 1 suggests one shape of this emerging theory.

Acknowledgements We acknowledge the support of the US National Science Foundation for the Baltimore Ecosystem Study, Long-Term Ecological Research project (DEB-1027188), and the Urban Sustainability Research Coordination Network (RCN1140070). We are grateful for the early stimulus provided by Parwinder Grewal and Loren Byrne, who invited us to present at the 2007 ecological landscaping conference sponsored by the Council of Educators in Landscape Architecture.

Open Access This article is distributed under the terms of the Creative Commons Attribution 4.0 International License (http:// creativecommons.org/licenses/by/4.0/), which permits unrestricted use, distribution, and reproduction in any medium, provided you give appropriate credit to the original author(s) and the source, provide a link to the Creative Commons license, and indicate if changes were made.

\section{References}

Alberti M (2008) Advances in urban ecology: integrating humans and ecological processes in urban ecosystems. Springer, New York

Cadenasso ML, Pickett STA (2008) Urban principles for ecological landscape design and management: scientific fundamentals. Cities Environ 1:Article 4. http://digitalcommons. lmu.edu/cate/vol1/iss $2 / 4$

Cadenasso ML, Pickett STA, Grove JM (2006) Integrative approaches to investigating human-natural systems: the Baltimore ecosystem study. Nat Sci Soc 14:4-14

Felson AJ, Bradford MA, Terway TM (2013) Promoting Earth stewardship through urban design experiments. Front Ecol Environ 11:362-367

Forman RTT (2008) Urban regions: ecology and planning beyond the city. Cambridge University Press, New York

Forman RTT (2014) Urban ecology: science of cities. Cambridge University Press, New York

Forman RTT (2016) Urban ecology principles: are urban ecology and natural area ecology really different? Landscape Ecol 31(8):1653-1662

Huang GL, Zhou WQ, Cadenasso ML (2011) Is everyone hot in the city? Spatial pattern of land surface temperatures, land cover and neighborhood socioeconomic characteristics in Baltimore, MD. J Environ Manag 92:1753-1759

Kaushal SS, Belt KT (2012) The urban watershed continuum: evolving spatial and temporal dimensions. Urban Ecosyst. doi:10.1007/s11252-012-0226-7
Lee T-W, Choi HS, Lee J (2014) Generalized scaling of urban heat island effect and its applications for energy consumption and renewable energy. Adv Meteorol 2014: e948306

Likens GE (1992) The ecosystem approach: its use and abuse. Ecology Institute, Oldendorf/Luhe

McGrath BP (ed) (2013) Urban design ecologies. Wiley, Hoboken

McGrath BP, Marshall V, Cadenasso ML, Grove JM, Pickett STA, Towers J (eds) (2007) Designing patch dynamics. Columbia University School of Architecture, Planning and Preservation, New York

McHale MR, Pickett STA, Barbosa O, Bunn DN, Cadenasso ML, Childers DL, Gartin M, Hess GR, Iwaniec DM, McPhearson T, Peterson MN, Poole AK, Rivers L, Shutters ST, Zhou W (2015) The new global urban realm: complex, connected, diffuse, and diverse social-ecological systems. Sustainability 7:5211-5240

McPhearson T, Pickett STA, Grimm NB, Niemelä J, Alberti M, Elmqvist T, Weber C, Breuste J, Haase D, Qureshi S (2016) Advancing urban ecology towards a science of cities. Bioscience 66:198-212

Meiners SJ, Cadenasso ML, Pickett STA (2015) An integrative approach to successional dynamics: tempo and mode in vegetation change. Cambridge University Press, New York

Melosi MV (2000) The sanitary city: environmental services in urban America from colonial times to the present. University of Pittsburgh Press, Pittsburgh

Musacchio LR (2009) Pattern: process metaphors for metropolitan landscapes. In: McDonnell MJ, Hahs A, Breuste J (eds) Ecology of cities and towns: a comparative approach. Cambridge University Press, New York, pp 484-502

Musacchio LR (2013) Key concepts and research priorities for landscape sustainability. Landscape Ecol 28:995-998

Nassauer JI (1995) Culture and changing landscape structure. Landscape Ecol 10:229-237

Niemelä J (1999) Is there a need for a theory of urban ecology? Urban Ecosyst 3:57-65

Niemelä J, Kotze J, Yli-Pelkonen V (2009) Comparative urban ecology: challenges and possibilities. In: McDonnell MJ, Hahs A, Breuste J (eds) Ecology of cities and towns: a comparative approach. Cambridge University Press, New York, pp 9-24

Pickett STA, Boone CG, McGrath BP, Cadenasso ML, Childers DL, Ogden LA, McHale M, Grove JM (2013) Ecological science and transformation to the sustainable city. Cities 32(Suppl 1):S10-S20

Pickett STA, Cadenasso ML (2012) Urban ecology. In: Leemans R (ed) Ecological systems: selected entries from the encyclopedia of sustainability science and technology. Springer, New York, pp 273-301

Pickett STA, Grove JM (2009) Urban ecosystems: what would Tansley do? Urban Ecosyst 12:1-8

Pickett STA, Kolasa J, Jones CG (2007) Ecological understanding, 2nd edn. Academic Press, San Diego

Rebele F (1994) Urban ecology and special features of urban ecosystems. Glob Ecol Biogeogr Lett 4:173-187

Scheiner SM, Willig MR (eds) (2011) The theory of ecology. University of Chicago Press, Chicago 
Seto KC, Reenberg A, Boone CG, Fragkias M, Haase D, Langanke T, Marcotullio P, Munroe DK, Olah B, Simon D (2012) Urban land teleconnections and sustainability. Proc Natl Acad Sci USA 109:7687-7692

Spirn AW (1984) The granite garden. Basic Books, New York Vannote RL, Minshall GW, Cummins KW, Sedell JR, Cushing CE (1980) River continuum concept. Can J Fish Aquat Sci 37:130-137
Wu JG, Xiang W-N, Zhao JZ (2014) Urban ecology in China: historical developments and future directions. Landsc Urban Plan 125:222-233 